Transcontinentales

continentales

Sociétés, idéologies, système mondial

$4 \mid 2007$

Amérique latine

\title{
Pays émergents
}

\section{(2) OpenEdition \\ 1 Journals}

Édition électronique

URL : http://journals.openedition.org/transcontinentales/1034

DOI : 10.4000/transcontinentales. 1034

ISBN : 978-2-7351-1565-5

ISSN : $1775-397 X$

\section{Éditeur}

Editions de la maison des sciences de l'homme

\section{Édition imprimée}

Date de publication : 1 juin 2007

Pagination : 184

ISBN : 978-2-200-92396-9

ISSN : $1950-1684$

\section{Référence électronique}

"Pays émergents », Transcontinentales [En ligne], 4 | 2007, document 23, mis en ligne le 11 mai 2011 consulté le 25 septembre 2020. URL : http://journals.openedition.org/transcontinentales/1034 ; DOI https://doi.org/10.4000/transcontinentales.1034

Tous droits réservés 


\section{OUVRAGES REÇUS}

Les ouvrages objets de comptes rendus ne sont pas mentionnés ici.

\section{AFRIQUE}

Ebrahim-Vally Rehana et Denis-Constant MARTIN, Viewing the New South Africa. Representaions of South Africa in Television Commercials, Johannesburg, IFAS (Les Nouveaux Cahiers de I'IFAS n9), novembre 2006, $94 \mathrm{p}$.

Morange Marianne, La question du logement à Mandela-City (ex. Port Elizabeth), Paris, Karthala-IFAS, 2006, 398 p.

\section{AFRIQUE DU NORD, MOYEN-ORIENT}

Jean Gaulmier, un orientaliste. Recueil de textes publiés dans le Bulletin d'études orientales (1929-1972), Damas, IFPO, 2006, 189 p.

At-Umarl Abdallah Khadem (éd.), La poésie dialectale chantée en Tihama (Yémen), Sanaa, CEFAS, 2006, $659+48$ p.

ARBACH Mounir et Jérémie Schiettecatte, Catalogue des pièces archéologiques et épigraphiques du Jawf au Musée narional de Sanaa, Paris - Sanaa, UNESCO-CEFAS, 2006, $164+72$ p., 69 planches.

DenIs Éric (dir.), Villes et urbanisation des provinces égyptiennes. Vers l'écoumènopolis ?, Paris - Le Caire, Karthala-CEDEJ, 2007, $440 \mathrm{p}$.

Dresch Paul, The Rules of Barat. Tribal Documents from Yemen, Sanaa, CEFAS-Deutsches Archäologisches Institut, 2006, 339 p.

DUPONT Anne-Laure, Gurgi Zaydan 1861-1914. Écrivain réformiste et témoin de la Renaissance arabe, Damas, IFPO, 2006, 760 p.

LAZARD Gilbert, Grammaire du Persan contemporain (nouvelle édition), Téhéran, Éditions Farhang Moaser-IFRI, 2006, 303 p.

Regourd Anne (dir.), Catalogue cumulé des bibliothèques de manuscrits de Zabid, fascicule I - Bibliothèque 'Abd al-Rahman alHadhrami, Sanaa, CEFAS, 2006, $208+17$ p.

RoBIN Christian-Julien et Muhammad 'Abd al-Rahim JAzIM, Le pèlerin des forteresses du savoir. Hommage au qadi Isma'il b. Ali al-
Akwa à l'occasion de son $85^{\circ}$ anniversaire (recueil d'articles), Sanaa, CEFAS, 2006, $404+185 \mathrm{p}$.

Traverso Véronique, Des échanges ordinaires à Damas: aspects de l'interaction en Arabe. Approche comparative et interculturelle, Lyon-Damas, Presses universitaires de Lyon-IFPO, 2006, 394 p.

\section{AMÉRIQUE LATINE}

Arce Sotelo Manuel, La danza de tijeras y el violin de Lucanas, Lima, IFÉA-Instituto de etnomusicologia-Pontificia universidad catolica del Peru, 2006, 168 p.

Carrera Damas German, Carole Leal Curiel, Georges Lomné et Frédéric Martinez, Mitos politicos en las sociedades andinas. Origenes, invenciones y ficciones, Lima, IFÉA et al., 2006, 420 p.

Chauchat Claude (éd.), Prehistoria de la costa norte del Peru. El paijanense de Cupisnique, Lima-Trujillo, IFÉA-Patronato Huacas del Valle de Moche, 2006, 413 p.

de las Mercedes del Rio Maria, Etnicidad, territorialidad y colonialismo en los Andes: tradicion y cambio entre los soras de los siglos XVI y XVII, La Paz-Lima, Instituto de estudios bolivianos-IFÉA, 2005, 341 p.

Demoraes Florent, Movilidad, elementos esenciales y riesgos en el distrito metropoliotano de Quito, Lima-Quito, IFÉA-Municipio del Ditrito metropolitano de Quito-IRD, 2005, $227 \mathrm{p}$.

Gavira Marquez Maria Concepcion, Historia de una crisis : la mineria en oruro a fines del periodo colonial, La Paz-Lima, Instituto de estudios bolivianos-IFÉA et al., 2005, $333 \mathrm{p}$.

O'PHelan Godoy Scarlett et Margarita Zegarra Florez (éds), Mujeres, familia y sociedad en la historia de America Latina, siglos XVIII-XXI, Lima, IFÉA-CENDOC Mujer -Instituto Riva-Agüero, 2006, 783 p.

SchlüPmAnN Jakob, Cartas edificantes sobre el comercio y la navegacion entre Peru y Chile a comienzos del siglo XVIII. Correspondencia y contabilidad de una compañia comercial (1712-1730), Lima, IFÉA et al., 2006, 346 p. 


\section{OUVRAGES REÇUS}

TAuzıN Isabelle (éd.), Manuel Gonzales Prada : escritor de dos mundos, Lima, IFÉA et al., 2006, 309 p.

TAYLOR Gerald, Diccionario quechua chachapoyas lamas, Lima, IFÉA-Instituto de estudios peruanos-Editorial commentarios, 2006, $146 \mathrm{p}$.

VAldez Francisco (éd.), Agricultura ancestral: camellones y albarradas. Contexto social, usos y retos del pasado y del presente (colloquio Agricultura prehispanica sistemas basados en el drenaje y en la elevacion de los suelos cultivados, Quito, junio 2003), Quito-Lima, Ediciones AbyaYala-IFÉA et al., 2006, 361 p.

\section{ASIE MÉRIDIONALE}

Berthet Samuel, Inde-France (1870-1962) : enjeux culturels, Pondichéry-New Delhi, IFP -CSH, 2006, $676 \mathrm{p}$.

Berthet Samuel, Cultural Dynamics and Strategies of the Indian Elite (1870-1947).
Indo-French Relations during the Raj, New Delhi, Manohar, 2006, 239 p.

\section{EUROPE}

Bulletin $n^{\circ} 42$, Göttingen, Wallstein Verlag -MHFA, 2006, 442 p.

Mériaux Charles, Gallia irradiata. Saints et sanctuaires dans le nord de la Gaule du haut Moyen Âge, Göttingen, Franz Steiner Verlag, 2006, $428 \mathrm{p}$.

Vincent Marie-Bénédicte, Serviteurs de I'État: les élites administratives en Prusse de 1871 à 1933, Paris, Belin, 2006, 367 p.

\section{PAYS ÉMERGENTS}

ChaKRABorty Debashis et Dipankar Sengupta, IBSAC (India, Brazil, South Africa, China): A Potential Developing Country Coalition in WTO Negotiations, New Delhi, CSH (CSH occasional paper $n^{\circ}$ 18), 2006, $162 \mathrm{p}$. 